\title{
Major Septal Defects: Comparative Study of Down Syndrome and Non-Down Syndrome Infants, Before and After Surgery
}

\author{
Saleha Aziz', Maaha Ayub², Laiba Masood ${ }^{3}$, Muneer Amanullah ${ }^{4}$, \\ Rukhsana Hameed ${ }^{5}$, Shiraz Hashmi ${ }^{6}$, Waris Ahmad ${ }^{7}$
}

\begin{abstract}
Objective: To compare pre-operative, intra-operative, and post-operative parameters in Down syndrome (DS) and non-DS patients with atrioventricular septal defects (AVSD) and inlet ventricular septal defects (VSD) in a tertiary care hospital in Pakistan.

Methods: We conducted a retrospective study at Aga Khan University, Pakistan. All complete atrioventricular septal defect (CAVSD), partial atrioventricular septal defect (PAVSD), and VSD with inlet extension surgical cases from January 2007 to January 2019 were included. Patients with congenital heart diseases other than those listed above were excluded.

Results: In 61 cases, 18 had DS. Median age, mean body surface area (BSA), and height were lower in DS patients compared to non-DS patients: 7.0 vs 23.0 months, 0.311 vs $0.487 \mathrm{~m} 2$, and 63 vs $82 \mathrm{~cm}$, respectively. Bypass duration, aortic cross clamp time, post-operative ventilator hours, dose of inotropes, $\mathrm{CICU}$ stay, and total hospital stay were all significantly higher in the DS group. The odds ratio $(95 \% \mathrm{Cl})$ for mortality in DS babies was $6.2(1.4,27.1), p=0.015$, after adjusting for age, weight, and height. The overall morbidity was comparable between the two groups, demonstrating no significant difference after adjusting for confounders.

Conclusion: DS babies with AVSD and inlet VSD are at a greater risk of mortality compared to non-DS babies, particularly those with CAVSD. Furthermore, DS babies undergo surgery at a younger age and require more aggressive post-operative therapy and monitoring due to the development of complications.
\end{abstract}

KEYWORDS: Down Syndrome, Septal Defects, Atrioventricular, Inlet VSD, AVSD, Endocardial Cushion Defect.

How to cite this:

doi: https://doi.org/10.12669/pjms.36.5.1743

Aziz S, Ayub M, Masood L, Amanullah M, Hameed R, Hashmi S, et al. Major Septal Defects: Comparative study of Down Syndrome and Non-Down Syndrome Infants, before and after surgery. Pak J Med Sci. 2020;36(5):925-929.

doi: https://doi.org/10.12669/pjms.36.5.1743

This is an Open Access article distributed under the terms of the Creative Commons Attribution License (http://creativecommons.org/licenses/by/3.0), which permits unrestricted use, distribution, and reproduction in any medium, provided the original work is properly cited.

Saleha Aziz, Medical Student

Maaha Ayub, Medical Student

Laiba Masood, Medical Student

Prof. Dr. Muneer Amanullah

Prof. of Pediatric Cardiothoracic Surgery, NICVD; Karachi, Pakistan.

Dr. Rukhsana Hameed

Head of Department, Maternal and Child Health,

Institute of Public Health, Lahore, Pakistan.

6. Shiraz Hashmi

Analyst, Cardiothoracic Surgery,

Dr. Waris Ahmad

Assistant Professor, Pediatric Cardiothoracic Surgery,

1-3,6,7: Aga Khan University, Karachi, Pakistan.

Correspondence:

Saleha Aziz

Medical Student, Aga Khan University, Karachi, Pakistan.

Email: salehaaziz95@gmail.com

* Received for Publication:

* Revision Received: Revision Accepted:
September 30, 2019

June 11,2020

June 15, 2020

\section{INTRODUCTION}

The most common congenital heart defects in Down syndrome (DS) babies are atrioventricular septal defects (AVSD) and ventricular septal defects (VSD) with a prevalence of $54 \%$ and $40 \%$, respectively. ${ }^{1}$ Numerous reports of association of inlet VSD with DS babies are also present as they are often found as a part of the AVSD complex. ${ }^{2}$ These septal defects typically appear in the fetus or neonate and are a significant cause of cardiac morbidity and mortality in this age group, especially in complete atrioventricular septal defects (CAVSD). ${ }^{3}$ 
Over the years, there has been a decline in the mortality and reoperation rates among patients undergoing surgical treatment for AVSD indicating overall improved outcomes due to better surgical technique and perioperative care. ${ }^{4,5}$ However, there are discrepancies in the clinical presentations and treatment outcomes of DS and non-DS patients with AVSD. The early postoperative morbidity rate among patients with DS and AVSD is higher while patients suffering from DS and CAVSD concurrently have a higher mortality risk compared to patients without these conditions. ${ }^{6}$ Considering the differences in various parameters among DS and non-DS patients with septal defects, it is important to assess and compare the pre-operative, intraoperative, and post-operative parameters of the two groups in loco-regional settings.

\section{METHODS}

We conducted a retrospective chart review at Aga Khan University Hospital, Karachi, Pakistan from January 2007 to January 2019 and found 61 cases that satisfied our inclusion and exclusion criteria. All CAVSD, PAVSD, and VSD with inlet extension surgical cases were included. All other congenital heart diseases or concomitant congenital heart diseases (two or more pathologies) were excluded. When data sets were normally distributed, we used mean and standard deviation as the measurements of central tendency, and independent sample t-test for comparing means of continuous variables between discrete data for two groups and oneway ANOVA test for more than two groups. In cases of non-normally distributed data, median and inter-quartile ranges were applied. For non-parametric data Mann Whitney $U$ test and Kruskal Wallis test were applied. The chi-squared test was used for the comparison of qualitative data. A multivariate logistic regression model was built to adjust for confounders. A p-value $<0.05$ was considered significant. All statistical analysis was performed using SPSS version 20.0 (IBM Corp., Armonk, N.Y., USA).

\section{RESULTS}

Our study included 61 patients, of which there were 32 male and 29 female babies. Amongst this population, $30 \%$ patients had DS. Descriptive analysis shows that patients with DS underwent surgery at a younger age, and had a smaller body surface area and height (Table-I). Comparisons of the common presenting complaints among the groups are shown in Fig.1.

Table-I: Pre, intra, and post-operative parameters in Down and non-Down syndrome.

\begin{tabular}{|c|c|c|c|}
\hline & $\begin{array}{c}\text { With Down } \\
\text { Syndrome }(n=18)\end{array}$ & $\begin{array}{c}\text { Without Down } \\
\text { Syndrome }(n=43)\end{array}$ & p-value \\
\hline Gender, n (\%) & & & 0.381 \\
\hline Male & $11(61 \%)$ & $21(49 \%)$ & \\
\hline Female & $7(39 \%)$ & $22(51 \%)$ & \\
\hline Age at surgery, median (IQR), months & $7(5-19)$ & $23(5-78)$ & 0.028 \\
\hline Weight, median (IQR), kg & $6(4-8)$ & $9(5-16)$ & 0.067 \\
\hline Height, median (IQR), cm & $63(59-76)$ & $82(65-114)$ & 0.011 \\
\hline Body surface area, median (IQR), $10-{ }^{2} \mathrm{~m}^{2}$ & $31.1(26.7-41.9)$ & 48.7 (29.5-77.7) & 0.037 \\
\hline Bypass time, median (IQR), minutes & 135 (95-185) & $108(80-130)$ & 0.024 \\
\hline Aortic cross clamp time, mean (SD), min & $105.3(39.3)$ & $77.5(41.8)$ & 0.019 \\
\hline Minimum temperature, mean (SD), ${ }^{\circ} \mathrm{C}$ & $32.1(1.6)$ & $32.4(1.9)$ & 0.489 \\
\hline Mortality, n (\%) & $9(50 \%)$ & $4(9 \%)$ & 0.001 \\
\hline CAVSD n $(\%)$ & $8(66.7 \%)$ & $0(0 \%)$ & \\
\hline VSD n $(\%)$ & $1(25 \%)$ & $4(23.5 \%)$ & \\
\hline PAVSD n $(\%)$ & $0(0 \%)$ & $0(0 \%)$ & \\
\hline Re-opening, $\mathrm{n}(\%)$ & $2(11 \%)$ & $1(2 \%)$ & 0.205 \\
\hline Ventilator support, n (\%) & $17(94 \%)$ & $32(74 \%)$ & 0.089 \\
\hline Ventilation hours, median (IQR), hours & $96.5(45.3-202.8)$ & $10.0(2.0-36.0)$ & $<0.001$ \\
\hline Inotrope administration, $\mathrm{n}(\%)$ & $17(94)$ & $35(81)$ & 0.259 \\
\hline Inotrope dose, median (IQR), $\mathrm{mcg} / \mathrm{kg} / \mathrm{min}$ & $6.5(1.0-16.3)$ & $3.0(0.0-5.0)$ & 0.026 \\
\hline CICU stay, median (IQR), days & $9(5-16)$ & $6(3-8)$ & 0.042 \\
\hline Total hospital stay, median (IQR), days & $11(8-22)$ & $8(7-15)$ & 0.033 \\
\hline
\end{tabular}




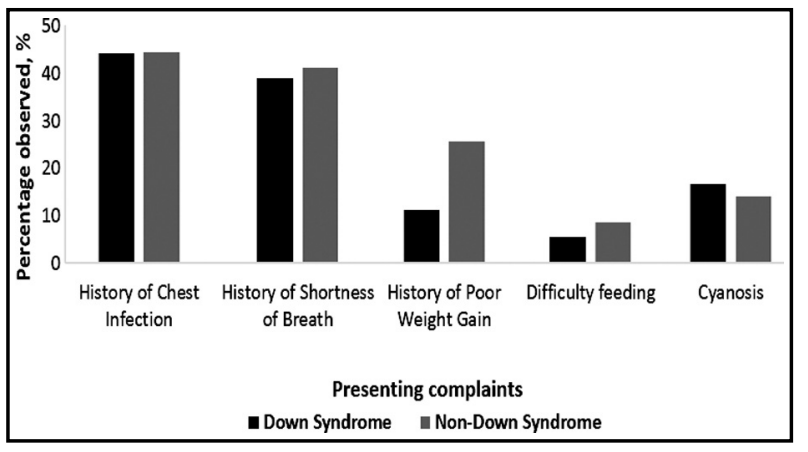

Fig.1: Comparison (proportion) of presenting complaints in Down vs. non-Down syndrome patients.

Intra-operatively, the bypass time and aortic cross clamp time were both significantly higher in the DS group $(p<0.05)$. Post-operatively, the hours of ventilator support, the administered dose of inotropes, along with the total CICU and hospital stay were all significantly greater in DS patients $(\mathrm{p}<0.05)$. Some of the commonly observed post-operative morbidities included arrhythmia, pleural effusion, pneumothorax, pulmonary hypertension, and sepsis which were more common in DS than non-DS patients. Other morbidities, including pericardial effusion and chest infections, were more common in the non-DS group. Both pleural and pericardial effusions were managed conservatively as well as via chest tube insertion, while pneumothorax was primarily managed via tube thoracostomy. Patient characteristics for pre-, intra-, and postoperative parameters in DS and non-DS patients are presented in Table-I.

The most prevalent defect was CAVSD, followed by VSD and PAVSD. DS patients had a greater prevalence of CAVSD compared to nonDS patients $(67 \%$ vs. $38 \%)$, whereas VSD was comparable ( $22 \%$ vs. $24 \%)$ and PAVSD was higher in non-DS patients ( $11 \%$ vs. $24 \%)$.

Overall operative mortality was $21.3 \%$, however, DS had a greater number of deaths as compared to non-DS [n (\%): 9 (50\%) vs. 4 (9\%)]. Furthermore, mortality was significantly associated with lower age $(p<0.001)$, height $(p=0.004)$, weight $(p=0.002)$, and body surface area $(p=0.002)$. The association of mortality and DS persisted after adjusting for age, height, and weight [(OR, 95\% CI) 6.2 (1.4, 27.1) $\mathrm{p}=0.015]$ (Table-II). Mortality rate of CAVSD patients in the DS group vs. non-DS group was $66.7 \%$ vs. $0 \%$ (Table-I). Moreover, the patients that did not survive had spent a significantly greater number of hours on ventilator support $(p=0.008)$. Common causes of mortality include cardiopulmonary arrest, sepsis, and arrhythmia.

Post-operative ventilator use was associated with inotrope administration $(p=0.001)$, specifically with higher doses of epinephrine $(p=0.014)$ and milrinone $(p=0.006)$ administered to patients on ventilator support. Patients on ventilator support also spent a significantly greater number of days in the CICU $(\mathrm{p}<0.001)$ and the hospital $(\mathrm{p}=0.002)$.

Patients with CAVSD and VSD were younger at the time of surgery and had lower weight, height, and body surface area $(\mathrm{p}<0.001)$. Bypass and aortic cross clamp times were both highest in CAVSD patients and lowest in VSD patients $(p<0.001)$, which suggests that CAVSD patients had more complex procedures. The minimum temperature during procedure was lowest in CAVSD patients and highest in VSD patients $\mathrm{p}=0.007$ (Table-III).

\section{DISCUSSION}

Congenital heart disease (CHD) is prevalent in $40 \%$ of patients with DS, and $0.3 \%$ in nonDS. ${ }^{78}$ The surgical correction of CHD in these patients usually involves greater risk of postoperative complications and mortality. ${ }^{9}$ Studies from Pakistan show that VSD and AVSD are the two most prevalent CHD in DS patients in the country (60.4\% vs. $29.1 \%)$, however, we found that CAVSD has the greatest prevalence in DS patients followed by VSD (67\% vs. $22 \%) .{ }^{10,11}$

Repair of partial atrioventricularcanal in Pakistan has good outcomes with minimal mortality. Moreover, early repair reduces post-operative morbidity and the cost of treatment. ${ }^{12,13}$ Most DS

Table-II: Univariate and multivariate logistic regression model for DS and non-DS.

\begin{tabular}{ccccc}
\hline \multirow{2}{*}{ Outcome variable } & \multicolumn{2}{c}{ Unadjusted } & \multicolumn{2}{c}{ Adjusted } \\
\cline { 2 - 5 } & OR $(95 \%$ CI $)$ & P value & OR $(95 \%$ CI) Adjusted & P value \\
\hline Mortality & $9.8(2.6,38.9)$ & 0.001 & $6.2(1.4,27.1)$ & 0.015 \\
Morbidity & $2.0(0.6,6.3)$ & 0.236 & $1.4(0.4,4.8)$ & 0.574 \\
\hline
\end{tabular}

${ }^{*}$ Adjusted for age, weight and height; "Arrhythmia, respiratory infection,

sepsis, pneumothorax, pleural and pericardial effusion, and pulmonary hypertension. 
Table III: Pre-, intra- and post-operative parameters of all patients by the type of defect.

\begin{tabular}{lcccc}
\hline & CAVSD $(n=28)$ & PAVSD $(n=12)$ & VSD $(n=21)$ & $p$-value \\
\hline Age at surgery, median (IQR), months & $6.0(10.5-66.8)$ & $102.5(60.0-156.0)$ & $7.0(4.0-18.5)$ & $<0.001$ \\
Weight, median (IQR), $\mathrm{kg}$ & $6.0(5.0-13.9)$ & $20.5(13.0-43.3)$ & $5.0(4.0-8.0)$ & $<0.001$ \\
Height, median (IQR), $\mathrm{cm}$ & $67.5(60.3-105.3)$ & $123.5(90.3-126.5)$ & $102.5(60.0-156.0)$ & $<0.001$ \\
Body surface area, median (IQR), $\mathrm{m}^{2}$ & $0.3(0.3-0.7)$ & $0.8(0.6-1.3)$ & $0.3(0.2-0.4)$ & $<0.001$ \\
Bypass time, median (IQR), minutes & $127.5(116.0-150.0)$ & $110.0(92.5-150.0)$ & $65.0(50.0-106.0)$ & $<0.001$ \\
Aortic cross clamp time, mean (SD), minutes & $108.1(37.7)$ & $97.2(39.3)$ & $49.4(23.1)$ & $<0.001$ \\
Minimum temperature, mean (SD), ${ }^{\circ} \mathrm{C}$ & $31.7(1.8)$ & $32.1(1.2)$ & $33.3(1.8)$ & 0.007 \\
Mortality, n (\%) & $8(29 \%)$ & $0(0 \%)$ & $5(24 \%)$ & 0.122 \\
Re-opening, $\mathrm{n}(\%)$ & $0(0 \%)$ & $1.0(8.3 \%)$ & $2.0(10.0 \%)$ & 0.259 \\
Ventilator support, n (\%) & $22(79 \%)$ & $9(75 \%)$ & $18(86 \%)$ & 0.720 \\
Ventilation hours, median (IQR), hours & $29.0(3.3-145.8)$ & $4.0(2.0-20.0)$ & $20.5(6.8-72.5)$ & 0.160 \\
Inotrope administration, $\mathrm{n}(\%)$ & $26(93 \%)$ & $9(75 \%)$ & $15(71 \%)$ & 0.273 \\
Total hospital stay, median (IQR), days & $9(7-19)$ & $7(6-10)$ & $10(7-15)$ & 0.343 \\
\hline
\end{tabular}

patients in our study underwent repair at less than one year of age, which is consistent with other studies around the world. ${ }^{14}$ However, despite early repair, the presence of DS in patients significantly increases the risk of severe morbidities that have a significant impact on the recovery period, as well as on life expectancy even after successful CHD correction. ${ }^{15}$ Our study shows trends of increased morbidity in the DS group, however, it did not reach statistical significance possibly due to small sample size.

The mortality rate in DS patients was significantly higher than non-DS patients, even after adjusting for confounders (age, weight, height). Within this mortality group, $61.5 \%$ of patients had a CAVSD. CAVSD is known to have poorer outcomes, longer median ventilation times, and intensive care unit and hospital stay (days), compared to other AVSD subtypes. ${ }^{3}$ Interestingly, we report no deaths in non-DS patients with CAVSD.

Western literature suggests that there is no significant difference or lower risk of mortality after AVSD correction in DS patients, which contrasts our findings.,16 This raises questions of possible differences in outcomes due to genetic, racial, environmental, and social factors which have not yet been explored in this region. This also highlights the need for developing indigenous guidelines for the management of these pathologies as currently practices from other countries (particularly from Western states) are being followed in Pakistan. Local guidelines were developed in India after the National Consensus Meeting on Management of Congenital Heart Diseases, 2018, which suggested that patients in the region are often underweight, malnourished, and have morbidities such as recurrent infections and anemia. Several patients present late with advanced level of pulmonary hypertension, ventricular dysfunction, hypoxia, and polycythemia. Therefore, the outcome after surgery in such patients has a greater possibility of being undesirable, justifying the need for revised guidelines and practices with a risk adjusted approach. ${ }^{17}$

DS and non-DS patients have no significant differences in pre-operative hemodynamics, however, post-operative right heart pressures and pulmonary vascular resistances have remained significantly high in DS patients compared to non-DS patients. ${ }^{18}$ This could be a result of lung hypoplasia in DS patients, which predisposes them to pulmonary hypertension, leading to longer ventilation times and increased post-operative morbidity. An increased cross-clamp time, as seen in our DS patient group, is also directly correlated with increased ventilation support. Furthermore, DS patients in our study had a significantly higher cardiopulmonary bypass time (CBPT) and aortic cross-clamp time (XCT), with longest durations in the CAVSD group. Longer CBPT and XCT reflect more complex surgeries, indicating that DS and CAVSD patients underwent a more difficult repair. ${ }^{19}$

Limitations of the study: The results of this study should be interpreted considering that this is a single center data analysis. Hence, reproducing the study on a larger scale, across multiple centers of the country, will yield more robust results. Since this study was conducted in one of the most urbanized areas of the country, socioeconomic 
parameters in the sample population may not be an accurate representation of the population at large. Furthermore, only inpatient mortality has been listed but close follow-up on the patients could shed more light on outpatient and late mortality as well.

\section{CONCLUSION}

DS babies with AVSD and inlet VSD are at a greater risk of mortality compared to non-DS babies, particularly those with CAVSD. Furthermore, DS babies undergo surgery at a younger age than non-DS babies and require more aggressive postoperative therapy and monitoring due to the development of complications.

Conflicts of interest: None.

\section{Grant support and financial disclosures: None.}

\section{REFERENCES}

1. Benhaourech S, Drighil A, Hammiri AE. Congenital heart disease and Down syndrome: various aspects of a confirmed association. Cardiovasc J Afr. 2016;27(5):287290.

2. Marino B, Papa M, Guccione P, Corno A, Marasini M, Calabro R. Ventricular septal defect in Down syndrome. Anatomic types and associated malformations. Am J Dis Child. 1990;144(5):544-545. doi: 10.1001/ archpedi.1990.02150290038021

3. Kaza AK, Colan SD, Jaggers J, Lu M, Atz AM, Sleeper LA, et al. Surgical interventions for atrioventricular septal defect subtypes: the pediatric heart network experience. Ann Thorac Surg. 2011;92(4):1468-1475; discussion 75 doi: 10.1016/j.athoracsur.2011.04.109

4. Atz AM, Hawkins JA, Lu M, Cohen MS, Colan SD, Jaggers J, et al. Surgical management of complete atrioventricular septal defect: Associations with surgical technique, age, and trisomy 21. J Thorac Cardiovasc Surg. 2011;141(6):1371-1379. doi: 10.1016/j.jtcvs.2010.08.093

5. Boneva RS BL, Moore CA, Yang Q, Correa A, Erickson JD. Mortality associated with congenital heart defects in the United States: trends and racial disparities, 19791997. Circulation. 2001;103:2376-2381. doi: 10.1161/01. CIR.103.19.2376

6. Sarısoy Ö AC, Tokel K, Özkan M, Türköz R, Aşlamacı S. Long-term outcomes in patients who underwent surgical correction for atrioventricular septal defect. Anatol J Cardiol. 2018;20:229-234. doi: 10.14744/ AnatolJCardiol.2018.39660

7. Holmes G. Gastrointestinal disorders in Down syndrome. Gastroenterol Hepatol Bed Bench. 2014;7(1):6-8.

8. Ferencz C, Rubin JD, McCarter RJ, Brenner JI, Neill CA, Perry LW, et al. Congenital heart disease: prevalence at live-birth. The Baltimore-Washington Infant Study. Am J Epidemiol 1985;121(1):31-36. doi: 10.1093/oxfordjournals. aje.a113979

9. Lal PS, Chavan B, Devendran VR, Varghese R, Murmu UC, Kumar RS. Surgical outcome of congenital heart disease in Down's syndrome. Asian Cardiovasc Thorac Ann. 2013;21(2):166-169.
10. Rizvi SF-u-H, Mustafa G, Kundi A, Khan MA. Prevalence of congenital heart disease in rural communities of Pakistan. J Ayub Med Coll Abbottabad. 2015;27(1):124-127.

11. Ahmad S, Sarwar I, Sajid NK. DOWN'S SYNDROME; Congenital heart disease in children, an experience in Faisalabad Pakistan. Prof Med J. 2013;20(6):898-903.

12. Waqar T, Riaz MU, Shuaib M. Surgical repair of partial atrioventricular septal defect. Pak J Med Sci. 2017;33(2):285-289. doi: 10.12669/ pjms.332.12094

13. Panni RZ, Ashfaq A, Amanullah MM. Earlier surgical intervention in congenital heart disease results in better outcome and resource utilization. BMC Health Serv Res. 2011;11:353. doi: 10.1186/1472-6963-11-353

14. Santos FCGB, Croti UA, Marchi CHD, Murakami AN, Brachine JDP, Borim BC, et al. Surgical Treatment for Congenital Heart Defects in Down Syndrome Patients. Braz J Cardiovasc Surg. 2019;34(1):1-7. doi: 10.21470/16789741-2018-0358

15. Tumanyan MR, Filaretova OV, Chechneva VV, Gulasaryan RS, Butrim IV, Bockeria LA. Repair of complete atrioventricular septal defect in infants with down syndrome: outcomes and long-term results. Pediatr Cardiol. 2015;36(1):71-75. doi: 10.1007/s00246-014-0966-7

16. Fudge JC Jr, Li S, Jaggers J, O'Brien SM, Peterson ED, Jacobs JP, et al. Congenital heart surgery outcomes in Down syndrome: analysis of a national clinical database. Pediatrics. 2010;126(2):315-322. doi:10.1542/ peds.2009-3245

17. Saxena A, Relan J, Agarwal R, Awasthy N, Azad S, Chakrabarty $\mathrm{M}$, et al. Indian guidelines for indications and timing of intervention for common congenital heart diseases: Revised and updated consensus statement of the Working group on management of congenital heart diseases. Ann Pediatr Cardiol. 2019;12(3):254-286. doi: 10.4103/apc.APC_32_19

18. Morris CD, Magilke D, Reller M. Down's syndrome affects results of surgical correction of complete atrioventricular canal. Pediatr Cardiol. 1992;13(2):80-84. doi: 10.1007/ BF00798209

19. Shultz B, Timek T, Davis AT, Heiser J, Murphy E, Willekes $\mathrm{C}$, et al. Outcomes in patients undergoing complex cardiac repairs with cross clamp times over 300 minutes. J Cardiothorac Surg. 2016;11(1):105. doi: 10.1186/s13019016-0501-4

\section{Authors' Contribution:}

SA: Idea conception, data collection, manuscript writing, responsible and accountable for integrity of the work.

MA: Data collection, entry, and analysis.

LM: Data collection and manuscript writing.

MAMA: Supervised and encouraged medical students to pursue this research.

$\mathrm{RH}$ : Critical revision of the article.

SH: Data analysis and interpretation.

WA: Supervised the findings of this work. 